\title{
Plataforma Mignone: Ambiente Virtual de Aprendiza- gem e Objetos de Aprendizagem Especializados para a Educação Musical
}

\author{
Mignone Platform: Virtual Learning Environment and Learning Objects Specialized \\ for Music Education \\ Fernando Pinhati \\ Universidade Federal do Estado do Rio de Janeiro \\ (UNIRIO) \\ fernando.junior@uniriotec.br \\ Sean W. M. Siqueira \\ Universidade Federal do Estado do Rio de Janeiro \\ (UNIRIO) \\ sean@uniriotec.br
}

\begin{abstract}
Resumo Atualmente, há uma demanda por recursos multimídia e sociais de forma integrada em ambientes de aprendizagem, o que é uma necessidade ainda maior na Educação Musical. Neste artigo descrevemos as particularidades da Educação Musical e apresentamos a Plataforma Mignone. Esta plataforma é constituída por uma arquitetura formal para o desenvolvimento de ambientes virtuais e de um modelo para criação facilitada de objetos (e atividades) de aprendizagem, ambos especializados para a área da música. Aqui detalhamos as diretrizes que guiam a construção do ambiente, bem como apresentamos mais detalhes do estudo de caso que foi realizado com 27 alunos do ensino médio de uma escola pública no Rio de Janeiro. A partir de análises quantitativas e qualitativas, foi possivel concluir que o oferecimento de recursos multimídia e sociais, estimulados pelo uso da Plataforma Mignone como guia tanto na construção do ambiente quanto na dos objetos de aprendizagem, influenciam indiretamente na aceitação de ambientes virtuais de aprendizagem para Educação Musical pelos alunos.
\end{abstract}

Palavras-Chave: Educação Musical, Modelo $C(L) A(S) P$, UTAUT, Aceitação de Tecnologias, Ambientes de Aprendizagem, Redes Sociais

\begin{abstract}
Nowadays, there is a great demand for multimedia and social resources in an integrated way in learning environments, which is a still bigger need for Music Education. In this scientific article we describe the particularities of Music Education and present the Mignone Platform. This platform is composed of a formal architecture for supporting the development of virtual learning environments and a model that makes easier the creation of learning objects (and activities), both the architecture and the model are specialized for the Music knowledge area. Here we detail the guidelines that guide the construction of the environment and we also present more details on the case study that was performed with 27 students from a public high school at Rio de Janeiro, which used a prototype to perform the learning activities that were built according to the Mignone Platform. The aim of the case study was to verify the students' acceptance of the Mignone Platform. From quantitative and qualitative analysis, it was possible to notice that the use of social and multimedia resources, stimulated by the use of the Mignone Platform, has an indirect influence on the students' acceptance of virtual learning environments for Music Education.
\end{abstract}

Keywords: Music Education, C(L)A(S)P Model, UTAUT, Technology Acceptance, Learning Environments, Social Networks 


\section{Introdução}

A Lei de Diretrizes e Bases da Educação Nacional (LDB) por meio da Lei 11.769/08 tornou obrigatória, a contar 3 anos a partir da data da sua publicação, a inclusão de atividades de Educação Musical no ensino fundamental e médio de escolas públicas e privadas do país. O estudo de tecnologias no apoio à realização de atividades de Educação Musical torna-se ainda mais relevante neste contexto, devido ao grande número de estudantes de ensino fundamental e médio existentes no país, cera de 40.000.000 de crianças e adolescentes [42], devido à escassez de professores licenciados especificamente em música (em 2006, eram apenas $13,2 \%$ do total que atuavam com educação musical) [17] e também à existência de poucos trabalhos nessa área [2].

O que se vê constantemente em tecnologias que apoiam a Educação Musical é a utilização de recursos com predominância de texto [26] ou de material didático de pouca qualidade, construídos com uso de sons de baixa fidelidade e muitas vezes não correspondentes aos conceitos de Educação Musical abordados [22], o que pode prejudicar a aprendizagem do aluno e desestimulá-lo [26]. Uma das razões para essa predominância está na grande complexidade envolvida na criação de recursos educacionais para a área musical, pois necessitam integrar o processamento de áudio, elementos teóricos, recursos colaborativos e vários outros componentes específicos [15], e, por isso, exigem soluções difíceis e muitas vezes inovadoras.

Outro problema é a baixa exploração de recursos sócio-colaborativos, possível consequência da falta de estudos empíricos focados no uso do computador como um elemento de suporte para um melhor aprendizado no domínio musical, através do seu uso no reforço de estratégias de colaboração [28], como, por exemplo, sobre o uso de redes sociais e suas consequências.

Em contraste com este contexto, observa-se o surgimento de uma população grande de indivíduos que apresentam características de Residentes digitais, constituída por aqueles que usam a Web com naturalidade no seu dia a dia, veem este espaço como um lugar que contém amigos e colegas onde podem compartilhar informações sobre vida pessoal, estudos e trabalho e onde projetam e mantêm constantemente sua identidade digital [43].

Um estudo realizado [36] com 30.616 estudantes universitários dos Estados Unidos, constatou que 90,3\% dos alunos dedicam tempo diariamente na utilização de redes sociais, característica comum na população de Residentes. Outro exemplo pode ser visto nas respostas a um questionário entregue a 24 alunos do curso de Licenciatura e Bacharelado em Música da UNIRIO, a fim de enten- der com que tecnologias gostariam de trabalhar em seus estudos [30]. A maioria dos alunos indicou recursos relacionados a vídeo, videoconferência, gravação de som, edição de som e de partituras, além de funcionalidades de integração com redes sociais, essa última indicando o interesse de conectar seus estudos com sua identidade digital.

Mas apenas o oferecimento de recursos multimídia e sociais não resolve o problema [2]. É necessário que os recursos sejam estruturados de uma forma mais próxima ao domínio de estudos, possibilitando uma utilização facilitada por professores conteudistas na elaboração das aulas e, consequentemente, afetando no aprendizado dos alunos. Além disso, é preciso pensar no reuso dos materiais educacionais produzidos, já que, por serem multimídia, são mais difíceis e mais custosos de construir [15]. E por último, é necessário pensar na integração dos recursos sonoros entre si, para que a execução deles pelos alunos não seja prejudicada pela sobreposição indevida de sons, e também na integração das funcionalidades oferecidas com plataformas já existentes e conhecidas pelos alunos, como a rede social Facebook, por exemplo.

Assim, foi definida como hipótese desta pesquisa: SE recursos educacionais sonoros e sociais forem disponibilizados em um ambiente de aprendizagem que proporcione a estruturação, reuso e integração deles, ENTÃO tais recursos influenciarão positivamente a Intenção de Uso do ambiente pelos alunos.

O conceito de Intenção de Uso citado é derivado de Intenção Comportamental de Uso. A Intenção Comportamental é definida como a probabilidade subjetiva de uma pessoa apresentar algum tipo de comportamento [14].

Para possibilitar que recursos educacionais sonoros e sociais fossem disponibilizados em um ambiente de aprendizagem que proporcione a estruturação, reuso e integração deles, foi necessário propor um modelo para construção de objetos de aprendizagem (OA), baseado no Modelo 3C [16] e no Modelo C(L)A(S)P [37], e por um Ambiente Virtual de Aprendizagem (AVA), que facilita o uso e reuso destes objetos, além de permitir a integração entre eles e com plataformas externas. Estes dois componentes, o modelo e o AVA propostos, formam a Plataforma Mignone.

Este artigo é uma extensão de [31], provendo mais detalhes das diretrizes que guiaram a construção do AVA com recursos musicais, colaborativos, especializados para a execução de atividades de Educação Musical. Também apresentamos mais detalhes do estudo de caso realizado que permitiu a análise da influência positiva da intenção 
de uso do ambiente pelos alunos.

Na seção 2, o modelo teórico é apresentado, descrevendo-se o contexto de aprendizagem colaborativa para Educação Musical, o Modelo 3C (um dos pilares do modelo proposto para apoiar a criação dos objetos de aprendizagem), além de particularidades da Educação musical, como a cognição musical e a teoria de Serafine, além do modelo $\mathrm{C}(\mathrm{L}) \mathrm{A}(\mathrm{S}) \mathrm{P}$ (este último representa o segundo pilar do modelo proposto por esta pesquisa). A Plataforma Mignone é apresentada na seção 3, que descreve o modelo proposto, chamado $3 \mathrm{C}-\mathrm{C}(\mathrm{L}) \mathrm{A}(\mathrm{S}) \mathrm{P}$, além da Arquitetura Mignone. Ainda na seção 3, apresentamos a arquitetura física do AVA que foi desenvolvido, descrevendo as tecnologias utilizadas. $\mathrm{O}$ estudo de caso é descrito na seção 4 e a análise sobre a intenção de uso do AVA e dos objetos 3C-C(L)A(S)P é apresentada na seção 5. Comparações deste trabalho com outros relacionados são mostradas na seção 6 . Por fim, a seção 7 traz as conclusões desta pesquisa e ilustra alguns possíveis trabalhos futuros.

\section{Fundamentação Teórica}

\subsection{Aprendizagem Colaborativa e o Modelo 3C}

Na Educação Musical, a aprendizagem colaborativa é bastante disseminada. Swanwick [37] recomenda as atividades colaborativas e indica que a interação entre os alunos é muito importante na aprendizagem musical. No que tange a atividade de composição musical, a troca de conhecimento derivada das possibilidades de improvisação de cada aluno através da aprendizagem colaborativa é importante para os alunos [7]. Além disso, a interação entre os alunos os tornam mais socializados, segundo a teoria de desenvolvimento sócio-cultural de Vygotsky [41], consequência benéfica principalmente quando se trata de crianças como aprendizes.

A colaboração na educação pode se vista como um tipo de filosofia, onde o professor identifica as habilidades de cada aluno, distribui responsabilidade e autoridade entre indivíduos do grupo e delega poder ao grupo para que eles constituam um consenso através da cooperação entre si [44]. É bem diferente da cooperação pura, entendida como um conjunto de processos mais diretos que auxiliam um grupo de estudantes a chegarem num objetivo desejado pelo professor [44]. Os dois modelos tem suas vantagens. Em [44], sugere-se o modelo cooperativo para formar conhecimentos fundamentais para posteriormente permitir expansões e formação de novo conhecimento através do modelo colaborativo. Dessa forma, em uma turma de estudantes de música que já possuem uma noção inicial e já falam um vocabulário mínimo comum, atividades com ênfase na colaboração podem produzir excelentes resultados.

Entre vários modelos de colaboração para uso em ambientes computacionais existentes, é possível citar o Modelo 3C [16], que foi utilizado neste trabalho. Sua escolha se deu pelo fato de apresentar uma visão simplificada dos elementos da colaboração e também por ser muito utilizado na área da Aprendizagem Colaborativa com Suporte Computacional (CSCL).

O Modelo 3C [16] é inspirado no trabalho de mesmo nome de Ellis et al. [10], porém com algumas alterações. Segundo o modelo, a construção da colaboração se dá através da conjugação de atividades de Comunicação, Coordenação e de Cooperação. A Comunicação é realizada através da troca de mensagens entre os envolvidos em uma atividade colaborativa. A Coordenação está relacionada às atividades de gerenciamento das mensagens e das tarefas cooperativas. Já a Cooperação se constrói na realização conjunta de tarefas pelos envolvidos na atividade colaborativa.

Segundo o Modelo 3C, em ambientes computacionais colaborativos é necessária a existência de aplicativos que ofereçam em conjunto funcionalidades de Comunicação, Cooperação e Coordenação para que exista efetivamente a colaboração e a percepção que a atividade está sendo realizada de forma colaborativa. $\mathrm{Na}$ CSCL, estes aplicativos colaborativos podem ser oferecidos por meio dos Ambientes Virtuais de Aprendizagem (AVA).

\subsection{Cognição Musical, Teoria de Serafine e Modelo C(L)A(S)P}

Entender como funciona a cognição musical, isto é, como ocorre o raciocínio e o aprendizado de conceitos relacionados à música, é muito importante sob o ponto de vista da Educação Musical. A partir do entendimento maior sobre como o conhecimento musical é absorvido pelo ser humano, é possível determinar práticas didáticas e pedagógicas mais eficazes na aprendizagem de música.

Existem vários estudos sobre o desenvolvimento cognitivo do aluno de música e muitos deles são embasados na teoria de Piaget, dos quais um dos mais importantes é o de Serafine [11]. Serafine [35] define música como cognição. Em sua teoria, a autora repassa todas as definições existentes de música e as contesta, indicando o seu ponto de vista. Segundo a autora, a música é entendida como a atividade de "pensar em som" ou "pensar com o som". Este pensamento é definido como uma atividade áudio-cognitiva, sendo a obra de arte, isto é, a música o resultado dele.

O fato de o pensamento musical ser uma atividade áudio-cognitiva indica que a presença do som é fundamental 
e exclui automaticamente todos os pensamentos que não o envolvam. O "som" neste caso pode ser tanto os sons produzidos de modo físico, através das fontes sonoras diversas, como também as imagens mentais de sons que ocorrem quando, por exemplo, relembra-se uma música conhecida. Neste exemplo, ouve-se a música relembrada "internamente", mesmo não existindo a presença física do som externamente [35].

Em sua teoria, todo o material inaudível é excluído do pensamento musical, ou seja, não contribuem para a construção da cognição musical. Visualizações de notação musical, imagens, descrição de características musicais, consciência da técnica de composição utilizada, informações sobre assuntos históricos e biográficos - principalmente quando não evocam nos alunos imagens sonoras mentais previamente desenvolvidas - são exemplos de materiais excluídos do pensamento musical [35].

Do lado oposto, as atividades de composição e apreciação musical são consideradas como exemplos máximos do pensamento musical, assim como a execução (performance), que é uma combinação das duas primeiras [35].

Desta forma, entende-se como um elemento fundamental na Educação Musical a existência ou a evocação do som, externo ou interno respectivamente. Logo, é importante que a construção de objetos de aprendizagem para Educação Musical contemple a oferta de elementos audíveis e que, se possível, as atividades estimulem a composição, a apreciação e a execução musical.

O Modelo C(L)A(S)P [37] - também referenciado como modelo $(\mathrm{T}) \mathrm{E}(\mathrm{C}) \mathrm{LA}$ em publicações brasileiras - é um modelo construtivista que indica cinco elementos que são essenciais na aprendizagem de música: $\mathrm{C}$ - Composition, A - Audition, $\mathrm{P}$ - Performance, (L) - Literature e (S) - Skill Aquisition. Os principais parâmetros (C, A e P) devem ser favorecidos pelo professor nas atividades educativas, em relação aos parâmetros (L) e (S). Porém, estes últimos devem estar sempre presente nas atividades, pois ajudam no domínio dos parâmetros principais [11]. A proposta de Swanwick é que os parâmetros C(L)A(S)P sejam interligados pelo professor nas atividades educativas.

A respeito dos parâmetros, a criação $(\mathrm{C})$ pode ser exercitada em atividades e jogos de aprendizado por meio do incentivo à composição de músicas e improvisação. A apreciação (A) está relacionada à audição de músicas com estéticas, culturas e de períodos variados. Muito mais que simplesmente ouvir, este parâmetro está focado na vivência musical e nas percepções do aluno sobre o material apreciado. O parâmetro execução (P) é abordado na prática de um instrumento musical, envolvendo interpretação e habilidades específicas [11].

O parâmetro da literatura ((L)) introduz a contextuali- zação histórica e teórica de composições e períodos musicais, além da análise musicológica. $\mathrm{O}$ elemento técnica ((S)) consiste no desenvolvimento das habilidades necessárias para um músico, como treinamento auditivo, rítmico, notação musical, técnicas de prática em conjunto e também nos conhecimentos específicos que são necessários para um determinado instrumento [11].

Em conjunto com os 5 parâmetros, o autor cita como também importante o trabalho de interação social entre os alunos e professores durante as atividades propostas [37].

\section{A Plataforma Mignone}

O termo plataforma foi utilizado neste trabalho como o conjunto de elementos especializados para a Educação Musical, que sejam adaptados às teorias e aos modelos de aprendizagem que fundamentam a proposta e que sejam também coerentes às soluções, tendências e problemas levantados na literatura.

A esta plataforma foi dado o nome de Plataforma Mignone. Este nome é uma referência ao grande compositor, regente, flautista e pianista brasileiro Francisco Mignone (1897 - 1986), responsável por relevantes obras musicais como, por exemplo, o bailado Maracatu do Chico Rei, a ópera o Contratador de Diamantes e a série Valsas de Esquina para piano solo, além de atuante na área de Educação Musical.

A Plataforma Mignone abrange tanto diretrizes para construção de Objetos de Aprendizagem (OA) quanto a especificação de um AVA, objetivando uma melhor integração entre os eles. Essa abordagem visa proporcionar um ambiente para o qual seja mais fácil construir OA e utilizá-los em atividades de Educação Musical. Além disso, esta divisão em duas propostas permite que OA já existentes, como os disponibilizados por sites especializados, vídeos do Youtube e aplicativos próprios para Educação Musical sejam adaptados facilmente e reutilizados dentro do AVA, centralizando o acesso a estes OA e permitindo um maior controle sobre as interações realizadas pelos alunos. Assim, procurou-se trabalhar na união dos benefícios de um modelo especializado para a construção facilitada de OA para Educação Musical, chamado de Modelo 3C-C(L)A(S)P, com uma arquitetura de AVA que fornecesse recursos colaborativos e sociais, chamada Arquitetura Mignone. Estes são os dois elementos tecnológicos que constituem a Plataforma Mignone.

A ideia é que a Plataforma Mignone seja utilizada pelos alunos que acessem o AVA através de computadores ou de dispositivos móveis. Dentro do AVA, os alunos encontrarão atividades de Educação Musical, aderentes ao Modelo $\mathrm{C}(\mathrm{L}) \mathrm{A}(\mathrm{S}) \mathrm{P}$, que foram compostas pelos $\mathrm{OA}$ desenvolvidos pelos professores conteudistas. Na construção destes $\mathrm{OA}$, os responsáveis são auxiliados pelo 
Modelo 3C-C(L)A(S)P, que oferece recursos C(L)A(S)P colaborativos para reuso, e pela Arquitetura Mignone, que permite a integração dos recursos $\mathrm{C}(\mathrm{L}) \mathrm{A}(\mathrm{S}) \mathrm{P}$ colaborativos com outros $\mathrm{OA}$, com funcionalidades de monitoramento/controle do AVA e com serviços externos, como sistemas de redes sociais por exemplo. Além disso, a Arquitetura Mignone facilita o reuso de OA externos, permitindo sua integração com outros OA no processo de criação de atividades de Educação Musical.

Como o objetivo da Plataforma Mignone é disponibilizar um ambiente de aprendizagem especializado para Educação Musical, não serão utilizados AVAs tradicionais neste trabalho, como o Moodle ou Sakai, já que os mesmos trazem ferramentas genéricas e carecem de recursos de interação social. Como os alunos de música preferem funcionalidades sociais oferecidas por plataformas externas [9] ou funcionalidades especializadas [30], optou-se por utilizar um ambiente novo, que já tem em seu núcleo as funcionalidades sociais (ex.: OpenSocial), e que pode ser utilizado como um ambiente além do AVA: o Personal Learning Environment (PLE). Os PLE são ambientes independentes de instituição/escola ou curso, onde o aluno possui seu próprio espaço para estudar a partir de atividades disponibilizadas por diversas fontes distintas e pode acompanhar seu próprio desenvolvimento educacional numa ideia de aprendizagem contínua, também chamada de lifelong learning [5].

O termo professor conteudista é utilizado neste trabalho para referir-se ao educador responsável pelo planejamento e elaboração das aulas e atividades a serem disponibilizadas em um AVA. Quando apenas o termo professor (ou professora) for utilizado, o texto estará se referindo ao educador formador, que executa as atividades em sala de aula (presencial ou virtual) e acompanha o desenvolvimento de cada aluno, tomando a providência pedagógica cabível em cada caso. Além destes, outro papel citado no texto é o do tutor, cuja definição utilizada neste trabalho é o do profissional que auxilia os alunos na execução das atividades e no entendimento do material educacional elaborado.

\subsection{Modelo 3C-C(L)A(S)P}

O modelo proposto, ilustrado pela Figura 1, foca-se não só na construção de $\mathrm{OA}$, mas principalmente na elaboração de atividades de aprendizagem com uma abordagem construtivista. Ele demanda que os objetos nele con- tidos sejam dinâmicos, manipulando de maneira integrada fontes sonoras e exibindo/emitindo os resultados da interação. É composto por três camadas: (i) a camada de componentes básicos, (ii) a de serviços especializados e (iii) a de aplicativos, ou recursos C(L)A(S)P. As duas primeiras são responsáveis pela integração com os recursos de colaboração providos pelo ambiente e a consequente disponibilização deles como serviços para serem utilizados pelos OA. Os componentes e serviços disponibilizados nessas duas camadas estão divididos em três categorias: Cooperação, Comunicação e Coordenação, visões da Colaboração propostas pelo Modelo 3C [16].

De maneira resumida, a camada de Componentes Básicos disponibiliza os recursos existentes no ambiente para serem consumidos por OA musicais construídos. Conectando mais de um Componente Básico ou associando um determinado Componente (ou recurso externo provido por serviço web) a um fim específico, forma-se um Serviço Especializado (segunda camada). A adequação ao Modelo 3C garante que os Componentes Básicos e Serviços Especializados sejam desenvolvidos pensando na colaboração. Dessa forma, estes recursos colaborativos podem ser utilizados na construção de recursos $\mathrm{C}(\mathrm{L}) \mathrm{A}(\mathrm{S}) \mathrm{P}$, papel da terceira camada, onde as funcionalidades são construídas e classificadas de acordo com o modelo $\mathrm{C}(\mathrm{L}) \mathrm{A}(\mathrm{S}) \mathrm{P}$. Ainda dentro da terceira camada, encontra-se a subcamada de Recursos Auxiliares (iv), onde são oferecidos recursos de interação social, conforme proposto pelo modelo teórico utilizado. Assim, recursos educacionais construídos utilizando esta proposta provêm elementos aderentes a um modelo construtivista de Educação Musical, que são integrados entre si inclusive no que diz respeito à manipulação de sons e que podem ser utilizados na elaboração de atividades educacionais mais efetivas, já que a utilização do modelo C(L)A(S)P na Educação Musical leva o aluno a experiências mais abrangentes, fazendo com que ele possa construir, de uma maneira adequada, o conhecimento musical necessário para a sua formação [37].

\subsection{Arquitetura Mignone}

O objetivo da Arquitetura Mignone é o estabelecimento de diretrizes para construção de um AVA com recursos musicais, colaborativos, especializados para a execução de atividades de Educação Musical de uma maneira estruturada, integrada e com possibilidade de reuso. A Figura 2 ilustra a arquitetura lógica proposta. 


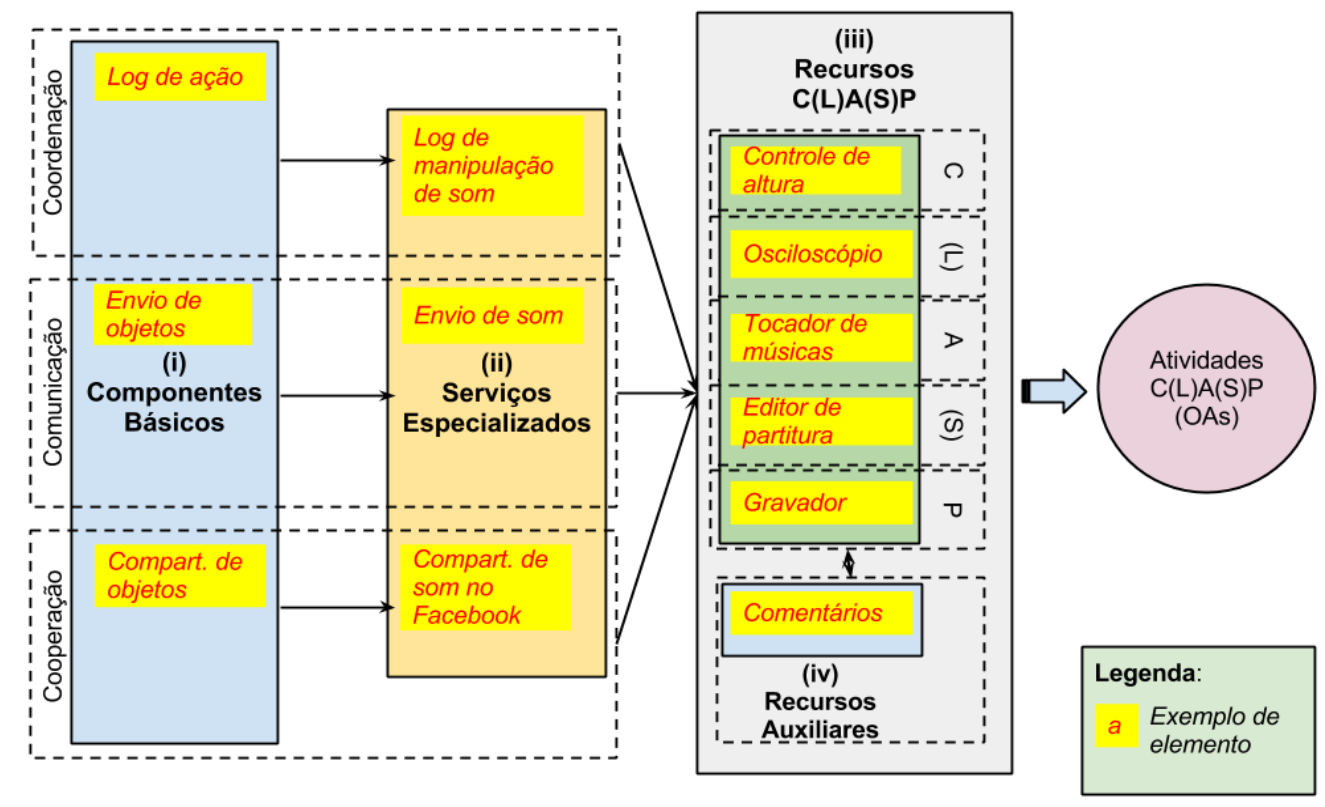

Figura 1: Modelo 3C-C(L)A(S)P

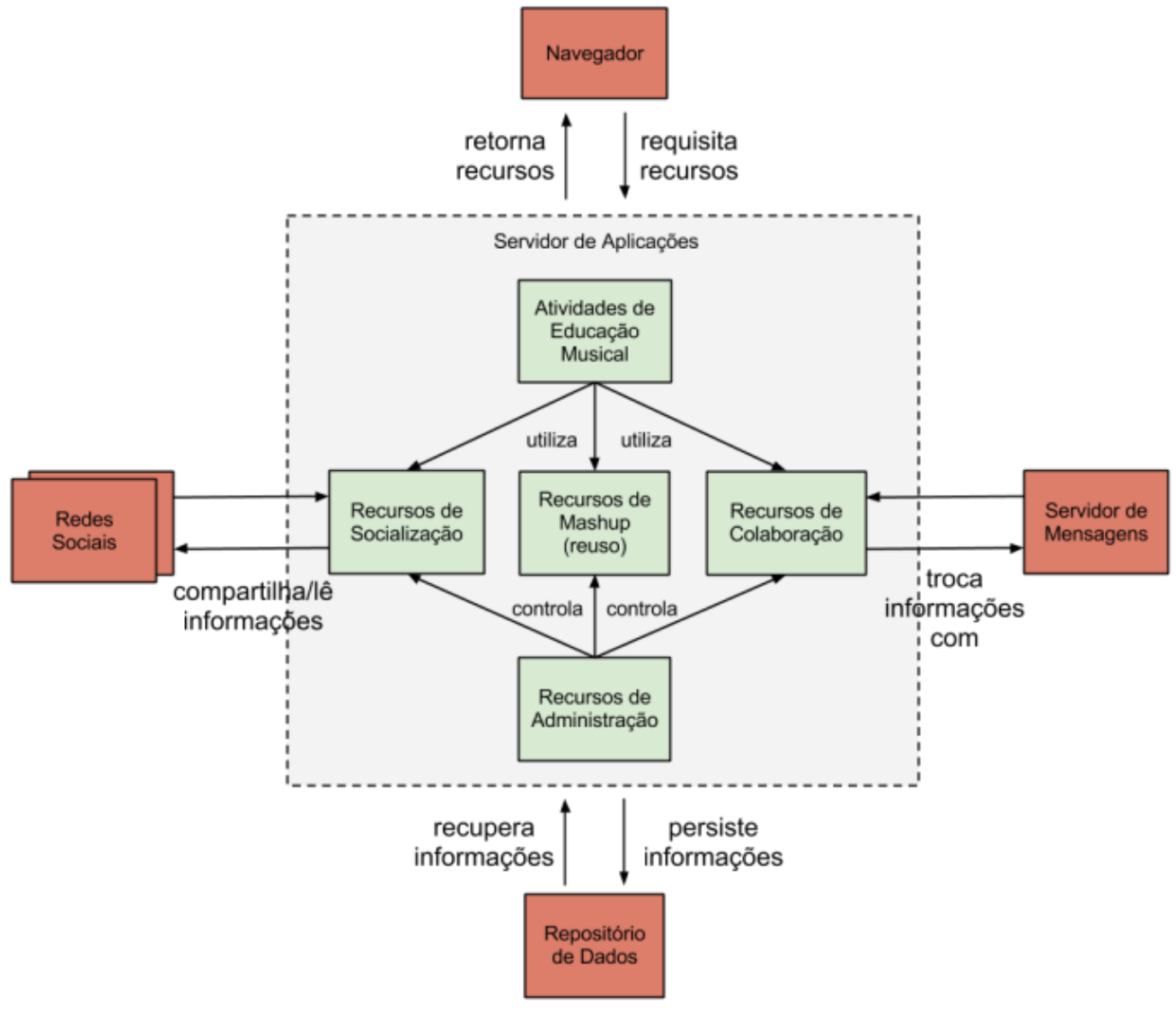

Figura 2: Arquitetura Mignone

Considerando os componentes que encontram-se fora do Servidor de Aplicações, o Navegador é o componente necessário para visualização do ambiente educacional proposto. O componente Servidor de Mensagens é responsável pela comunicação remota de dados entre dois recursos colaborativos. Ele permite que os dados de um 
aplicativo em execução por um aluno sejam enviados a outro aplicativo, também dentro do ambiente e que esteja sendo executado por outro estudante, mesmo que os dois estejam em lugares diferentes (remotos). O componente Redes Sociais é constituído de aplicações externas com as quais o ambiente educacional proposto deve compartilhar e obter informações sociais. Finalmente, o Repositório de Dados é o componente onde as informações provenientes do ambiente educacional são persistidas.

O componente Servidor de Aplicações é o responsável por receber as requisições de atividades educacionais efetuadas a partir do Navegador e processá-las de maneira adequada.

As Atividades de Educação Musical são pacotes de aplicações e de recursos educacionais, entregues através do Navegador, que são trabalhadas pelo professor com seus alunos. Elas são criadas a partir dos objetos de aprendizagem disponibilizados no ambiente, construídos com as diretrizes do Modelo 3C-C(L)A(S)P. Utilizam os Recursos de Colaboração, de Socialização e de Mashup disponíveis no Servidor de Aplicações e são aderentes ao modelo C(L)A(S)P para Educação Musical.

Os Recursos de Socialização são compostos por um conjunto de componentes básicos e serviços especializados que implementam, além da integração com redes sociais, os recursos sociais oferecidos dentro do próprio ambiente. Tais serviços permitem a exportação e a importação de informações do ambiente a partir de/para redes sociais.

O conceito mashup está associado com a construção de um novo serviço a partir da combinação de serviços já existentes. A ideia dos Recursos de Mashup é permitir a reutilização de itens externos à Plataforma Mignone dentro do ambiente, sejam estes itens softwares utilitários como aplicativos de chat, edição de som - ou objetos de aprendizagem - como vídeos, animações em flash, textos, links, imagens, sons, músicas, entre outros.

Os Recursos de Colaboração seguem o Modelo 3C são compostos por serviços e aplicativos que possibilitam que as atividades de Educação Musical sejam colaborativas. Provêm mecanismos de comunicação entre participantes, ferramentas para percepção de presença e modificação remota de itens compartilhados, serviços para trabalho colaborativo com objetos compartilhados e também recursos de coordenação.

Finalmente, os Recursos de Administração não estão ligados diretamente às atividades de aprendizagem, mas sim ao controle do AVA. São serviços de administração do ambiente, como definição de usuários, aplicativos, permissões de acesso, repositório de aplicativos, configuração de páginas, cursos, grupos, entre outros.

\subsection{Tecnologias Empregadas na Construção do AVA}

O Navegador deve suportar a especificação HTML5 (Hyper Text Markup Language, versão 5), para que seja possível a visualização e manipulação correta do AVA Mignone, e também a JavaScript API (Application Programming Interface) Web Audio, pois os recursos construídos a utilizarão na geração de sons.

Alguns dos componentes do AVA implementado foram inspirados em um estudo técnico realizado com o projeto ROLE-Project (Responsive Open Learning Pro$j e c t)^{1}$, sendo inclusive reutilizados alguns recursos.

Definiu-se a linguagem Java para os softwares construídos ou adaptados neste trabalho. Para o servidor de aplicações, foi escolhido o software Apache Tomcat 7 por sua simplicidade e por sua familiaridade de uso pela equipe de desenvolvimento. A maioria dos componentes da arquitetura consiste em aplicações que rodam dentro do servidor Apache Tomcat 7, como o Apache Rave ${ }^{2}$, o CamWebService ${ }^{3}$, o Repositório de Aplicativos, o Apache Shindig ${ }^{4}$, o Apache Wookie ${ }^{5}$ e o AVA Mignone.

O AVA desenvolvido (AVA Mignone) consiste nas extensões e adaptações efetuadas no Apache Rave a fim de alcançar os objetivos de colaboração e de execução de atividades musicais. Utiliza tanto funcionalidades externas - oferecidas por outros componentes como o CamWebService - quanto internas ao Rave, que é a sua base. O objetivo deste componente é ser a porta de entrada da Plataforma Mignone e oferecer todos os recursos necessários para a execução de atividades de Educação Musical, sendo assim o AVA utilizado pelos alunos.

O Apache Rave (ou apenas Rave) é um projeto da Apache Software Foundation (ASF) e tem como objetivo disponibilizar um ambiente web com interface amigável onde se possa manipular aplicativos sociais e criar mashups. Ele provê um recurso de processamento de aplicativos, também chamado de container, compatível com as especificações OpenSocial ${ }^{6}$ e W3C Widgets ${ }^{7}$,

\footnotetext{
1 2

http://www.role-project.eu/

https://rave.apache.org/

https://sites.google.com/site/camschema/home/cam-webservice

http://shindig.apache.org

http://wookie.apache.org

6

http://docs.opensocial.org/display/OS/Home

http://www.w3.org/TR/widgets/
} 
além de ter como objetivo futuro a integração com o Apache Wave, que implementa o Wave Protocol ${ }^{8}$.

Como Provedor OpenSocial, o Rave utiliza outro produto da ASF, chamado Apache Shindig. Este mesmo servidor é utilizado por vários outras plataformas sociais, como o Eureka Streams ${ }^{9}$, o Graasp ${ }^{10}$ e o ROLE-Project. Já o provimento da especificação $\mathrm{W} 3 \mathrm{C}$ Widgets é realizado por outro software da Apache, chamado Apache Wookie, com o qual o Rave também se comunica para efetuar o processamento dos widgets escritos neste formato.

Antes de decidir pelo uso do Apache Rave, vários outros softwares que possuíam possibilidade de integração com Apache Shindig foram estudados. Após estudos com ambientes como o ROLE-Project, Eureka Streams, Sa$\mathrm{kai}^{11}$, Moodle ${ }^{12}$ e Liferay Portal ${ }^{13}$, o Apache Rave foi escolhido como plataforma por possuir uma maior integração com o Apache Shindig, por ter uma comunidade ativa de desenvolvedores e por possuir um código-fonte mais estruturado e documentado em comparação com os outros projetos analisados.

A especificação OpenSocial é a mais difundida e utilizada atualmente. Já as especificações W3C Widgets e WaveProtocol são padrões que vêm obtendo cada vez mais destaque da comunidade de usuários, mas ainda não possuem grande utilização.

O Rave é o principal componente da solução arquitetural proposta. É a partir dele que extensões foram desenvolvidas e novos componentes foram derivados. Por ser concebido como um portal extensível e customizável, o Rave é também responsável pela interface gráfica com o usuário, autenticação e autorização da Plataforma Mignone.

O componente CamWebService é um aplicativo web desenvolvido pelo projeto $\mathrm{CAM}^{14}$ (Contextualized Attention Metadata) que permite o armazenamento em banco de dados das informações de monitoramento, capturadas de maneira rápida e transparente. $\mathrm{O}$ monitoramento realizado pelo AVA Mignone acessa o serviço web disponibi-

\footnotetext{
8

http://incubator.apache.org/wave/

10

http://eurekastreams.org/

http://graasp.epfl.ch

12

http://www.sakaiproject.org

http://www.moodle.org

http://www.liferay.com/

https://sites.google.com/site/camschema/
}

lizado pelo CamWebService, através da interface Recursos de Monitoramento, que por sua vez armazena as informações de evento, entidade e sessão no Repositório de Dados da plataforma.

O componente escolhido para repositório de dados foi o servidor de banco de dados MySQL, por ser rápido e apresentar todos os requisitos que as aplicações que com ele se comunica necessitam.

O componente Repositório de Aplicativos é constituído de um espaço dentro do Servidor de Aplicações para armazenamento dos widgets, que são utilizados tanto na construção de atividades de Educação Musical quanto no controle do ambiente. Estes widgets são arquivos XML, no formato OpenSocial ou W3C Widgets, e podem referenciar outros tipos de recursos, como imagens, sons e arquivos JavaScript.

Para o Servidor de Mensagens, definiu-se a necessidade da compatibilidade com o protocolo de comunicação em tempo real XMPP (Extensible Messaging and Presence Protocol) ${ }^{15}$. Este protocolo foi escolhido por ser livre e bastante utilizado, principalmente em serviços de mensageria corporativa e pelos mensageiros instantâneos derivados do serviço Jabber ${ }^{16}$. Como implementador deste componente, foi escolhido o software Openfire ${ }^{17}$.

Além dos recursos e serviços oferecidos pelo CamWebService e pelo Apache Rave, algumas outras funcionalidades foram desenvolvidas por meio de serviços web chamados Mignone Services. Eles consistem basicamente em dois tipos de serviços: transmissão (upload/download) de arquivos de áudio e captura de dados do ambiente Rave. A primeira categoria foi necessária para a confecção de alguns recursos e Aplicativos especializados, com o objetivo de permitir a ligação com diretrizes do Modelo 3C-C(L)A(S)P. Já a segunda permite que alguns Aplicativos Auxiliares de controle, que utilizam dados do Apache Rave no seu funcionamento, sejam construídos.

\section{Estudo de Caso}

Um estudo de caso foi realizado com 27 alunos de uma escola pública federal do Rio de Janeiro que possui Educação Musical em seu currículo. Foram realizadas atividades dentro da Plataforma Mignone complementares às aulas tradicionais de Educação Musical Básica. Os alunos tiveram aula presencial com a professora sobre
15
http://xmpp.org
17
http://www.jabber.org
http://www.igniterealtime.org/projects/openfire/ 
temas prévios ao assunto escolhido, nos modelos cooperativos e colaborativos, e a formação de um vocabulário comum mínimo aconteceu em sala de aula.

$\mathrm{O}$ assunto escolhido para o estudo foi "Parâmetros do Som". A escolha deste tema deu-se em conjunto com a professora dos alunos, que viu na utilização de tecnologias a possibilidade de explicar melhor alguns conceitos relacionados aos parâmetros do som que são difíceis de serem abordados em sala de aula. Além disso, a realização das atividades complementares foi vista também como de grande valia pela professora devido a uma greve que paralisou a instituição de ensino durante um longo período e prejudicou bastante o número de aulas presenciais de Educação Musical naquele semestre. Os objetos de aprendizagem construídos foram baseados no método de ensino da própria escola. A unidade de análise do estudo de caso foi a execução individual, de cada aluno, de todas as atividades propostas nos módulos do curso. Foram verificados os impactos da participação dos outros alunos simultaneamente e a interação entre eles no desempenho individual do aluno. A pesquisa foi registrada no comitê de ética e pesquisa da escola e autorizada pela instituição, pela professora, pelos alunos e por seus responsáveis.

Foram construídos 10 OA, divididos em 6 módulos distintos dentro do AVA. Eles utilizaram os recursos disponibilizados e classificados pelo modelo $3 \mathrm{C}-\mathrm{C}(\mathrm{L}) \mathrm{A}(\mathrm{S}) \mathrm{P}$ na sua construção. Mais detalhes especificamente sobre os OA e o funcionamento dos recursos podem ser encontrados em [29]. Um exemplo de OA construído, sobre o parâmetro do som "Altura", pode ser visualizado na Figura 3.

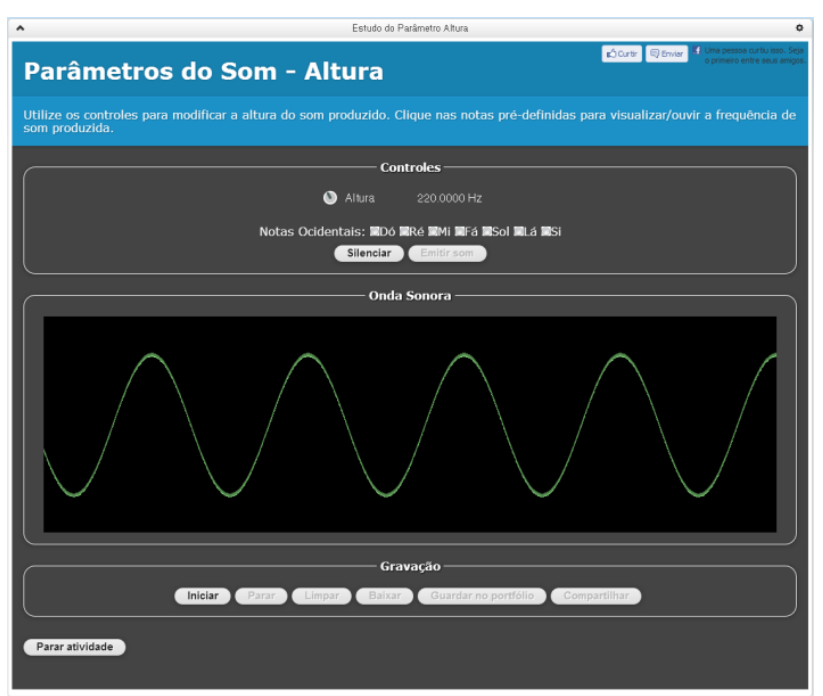

Figura 3: Exemplo de um OA construído

Primeiramente, o protótipo implementado foi disponibilizado em um servidor web. Um endereço público para acesso à plataforma foi configurado e a plataforma foi devidamente testada.

Com a infraestrutura configurada, testada e disponibilizada, a Plataforma Mignone foi apresentada aos alunos participantes. A apresentação foi presencial, na própria escola alvo e durou aproximadamente 10 minutos. O primeiro objetivo da apresentação foi verificar se todos os alunos possuíam os requisitos necessários para acessarem a Plataforma Mignone, como por exemplo uma conta no Facebook e a utilização do navegador Google Chrome. A partir disso, uma verificação prévia da característica de Residente foi realizada, já que uma das premissas para participar do estudo era possuir uma identidade digital mantida no Facebook. Apenas um aluno indicou que não poderia participar da pesquisa devido a problemas em seu computador em casa.

O segundo objetivo da apresentação foi mostrar aos alunos, de maneira geral, como navegar pelo ambiente. Foi dado o endereço de acesso à Plataforma Mignone aos alunos, apresentado o conceito de abas (que representam os módulos) e, como exemplo, a atividade Som x Ruído foi exibida, sem qualquer manipulação. Contatos para esclarecerem possíveis dúvidas foram deixados e os alunos foram orientados a conversarem com a professora na existência de qualquer dúvida ou problema.

Após a apresentação inicial, os alunos já estavam liberados para acessarem a Plataforma Mignone. O acesso deveria ser feito a partir dos computadores domésticos de cada aluno, à hora que desejassem. Foi necessário compartilhar os módulos do curso à medida que os alunos iam se cadastrando e entrando na plataforma, para que então eles pudessem visualizar as atividades complementares propostas. Este procedimento foi explicado durante a apresentação presencial do ambiente e foi realizado manualmente pelo autor dessa pesquisa. Para entrar na plataforma, o aluno deveria entrar com sua conta do Facebook.

Assim que alunos obtiveram acesso aos módulos do curso, puderam visualizar os objetos de aprendizagem disponibilizados no ambiente e entrar em contato com as funcionalidades oferecidas pela plataforma. Essas atividades complementares foram disponibilizadas para os alunos por um período de quatro semanas, equivalente a quatro aulas. Os alunos puderam acessar livremente a plataforma, quantas vezes fossem necessárias.

A professora teve papel fundamental na moderação e na condução do estudo com os alunos. Ela foi o ponto de contato com os estudantes para o esclarecimento de dúvidas sobre as atividades, identificação de grupos, recomendação de leituras e troca de experiências, trabalhando de um modo colaborativo. Para que os estudantes cumprissem todas as atividades no período de greve, o cumprimento delas foi premiado com pontos extras.

A faixa etária dos participantes desta pesquisa foi de 
14 a 16 anos, todos Residentes. Indivíduos de ambos os sexos participaram da pesquisa, sendo 14 homens e 13 mulheres. Estes participantes correspondem aos alunos de duas turmas distintas do curso de Educação Musical da escola citada.

Todos os alunos possuem bons conhecimentos em uso de tecnologias no dia-a-dia. Muitos deles utilizam computadores, tablets e celulares com frequência e alguns até já substituem o caderno pelo tablet em sala de aula. Nenhum dos alunos teve dificuldade no acesso à Plataforma por desconhecimento das funcionalidades do Facebook ou pela utilização do navegador Google Chrome.

Os 6 módulos oferecidos no ambiente possuíam objetos de aprendizagem que poderiam ser utilizados livremente pelos estudantes, além de um painel com comentários (via Facebook) onde os alunos deveriam postar suas experiências e conclusões sobre os objetos de aprendizagem e parâmetros musicais estudados. Individualmente, cada aluno teve sua experiência com os OA executados. Coletivamente, porém, todos eles interagiram através do painel de comentários, desde a simples leitura das colocações dos colegas até ações sociais, como respostas diretas e "curtir". Não havia um chat disponível na plataforma, mas alguns alunos indicaram que conversavam com colegas durante a execução dos OA (provavelmente através de redes sociais) ou até mesmo presencialmente, quando ocorriam aulas. Esses foram os canais de troca escolhidos pelos próprios estudantes.

As atividades foram dadas como concluída pela professora quando o aluno terminasse de comentar a sua experiência em todos os módulos.

\section{Análise da Intenção de Uso do AVA}

Durante o período das atividades, todas as ações executadas pelos alunos dentro da Plataforma Mignone foram monitoradas e armazenadas através de logs automatizados. Como processo de coleta de dados para análise qualitativa, entrevistas individuais foram agendadas com 13 alunos após as quatro semanas de atividades. O método de entrevista on-line [27] foi escolhido. Esse número de entrevistados foi suficiente para identificar a saturação nas respostas [21]. Para análise destes dados, foi utilizado o método MEDS, ou Método de Extração do Discurso Subjacente [27], que é uma técnica de análise de dados qualitativa baseada na extração de informações a partir de dados coletados por entrevistas.

Como guia na identificação de padrões a partir das entrevistas, os conceitos do modelo UTAUT - Unified Theory of Acceptance and Use of Technology [39], e consequentes adaptações, foram utilizados. Este modelo unifica várias teorias sobre aceitação de tecnologias e possui grande representatividade na medição de aceitação de sistemas de informação para as mais diversas áreas [40], motivo pelo qual foi o escolhido dentre outros levantados. O objetivo da identificação de padrões relacionados aos construtos do modelo UTAUT foi tentar entender quais características são mais importantes, na visão do aluno, na decisão de usar ou não ambientes virtuais de aprendizagem para a Educação Musical. No contexto desta pesquisa, procurou-se também entender se a forma na qual o ambiente foi construído e organizado, se o Modelo 3C$\mathrm{C}(\mathrm{L}) \mathrm{A}(\mathrm{S}) \mathrm{P}$ para a confecção de $\mathrm{OA}$, e se a aproximação do domínio da música e da realidade digital social do aluno influenciam, direta ou indiretamente, a Intenção de Uso.

Simplificadamente, os conceitos do UTAUT analisados e adaptados ao contexto do trabalho podem ser definidos como: (i) Oportunidade de Aprendizado é a visão do potencial do ambiente fornecer oportunidades de aprender, ligado à utilidade do ponto de vista educacional [6]; (ii) Influência Social é quanto o aluno percebe que amigos acham importante usar a tecnologia proposta nos seus estudos [39]; (iii) Facilidade de Uso é quanto é fácil utilizar a tecnologia proposta nos estudos [39]; (iv) Motivação Hedônica é quanto o aluno percebe divertimento utilizando a tecnologia [40]; (v) Condições Facilitadoras são quanto o aluno percebe que será auxiliado na utilização da tecnologia; e (vi) Intenção de Uso é um construto influenciado diretamente por todos os anteriores segundo o modelo UTAUT.

Seguem abaixo algumas falas selecionadas das entrevistas que justificam os achados encontrados nesta pesquisa.

A maioria dos entrevistados parece ter visto o uso de recursos de manipulação de som (parâmetros $\mathrm{C}$ e $\mathrm{A}$ do modelo $\mathrm{C}(\mathrm{L}) \mathrm{A}(\mathrm{S}) \mathrm{P})$ em associação com o recurso de visualização da onda sonora (parâmetro (L)) como características importantes na percepção da Oportunidade de Aprendizado. Segundo eles, o entendimento dos parâmetros do som foi facilitado pela experiência de modificar e visualizar o som de forma livre:

"A atividade se tornou mais fácil pela visão e audição, ficou mais completa do que se estivéssemos apenas vendo ou ouvindo." (Aluno APM)

Alguns alunos se manifestaram sobre a ideia de Influência Social, embora alguns tenham indicado que compartilhariam seus estudos para os seus amigos mas não o fizeram no ambiente:

"Bom acho que os meus estudos foram bem interessantes, logo eu publiquei-os.” (Aluno CG)

Alguns alunos perceberam a proximidade do domínio musical, a integração com o Facebook e a estrutura do ambiente como Condições Facilitadoras: 
"Não, eu fiquei confusa no inicio, são muitas informações. Mas não é difícil, pelo contrário. Quando você começa a mexer nas coisas que mais te chamam atenção, como os joguinhos(para mim), fica fácil. Não tem nada no site difícil de entender ou mexer. Até a disposição das coisas no site eu achei legal. Aquela janela que fica no lado direito com as publicações de todo mundo, a proximidade com o facebook de algumas coisas, eu achei bem inteligente. Para mim, pareceu uma forma de atrair mais atenção das pessoas e de nós alunos e que foi ótima, funciounou." (Aluno BB)

"O q mais me interessou foi como eu já disse, o formato do ambiente e a sincronização com o Facebook." (Aluno BC)

Alguns entrevistados perceberam a manipulação de recursos sonoros como atividade divertida (Motivação Hedônica):

"Quando você mostrou, achei diferente, nunca tinha visto algo nem próximo. Pensei que seria muito interessante. E realmente foi. Era uma nova forma de aprender e de uma maneira mais prazerosa, na prática, ao mexer com os controles e percebendo a variação do som." (Aluno GA)

Muitos alunos tiveram problemas de acesso ao ambiente que, segundo eles, apresentou falhas em algum momento. Oito dos treze entrevistados relataram algum tipo de problema no uso do ambiente. Alguns alunos indicaram tais falhas como elementos desmotivadores:

[O que menos gostou?] "No meu caso o servidor bloqueou algumas vezes o site, o que me impedia de fazer as atividades." (Aluno CA)

A percepção de Oportunidades de Aprendizado parece ter tido grande contribuição na Intenção de Uso. Vários alunos indicaram aspectos de aprendizado na decisão de continuar ou não utilizando o sistema ou de recomendá-lo a alguém:

"Acho que deve ser utilizado bastante esses recursos para a aprendizagem da educação musical e de todas as matérias. Pois além de aumentar o interesse do aluno, tbm facilita na aprendizagem." (Aluno GC)

De acordo com a análise realizada, os construtos adaptados Oportunidades de Aprendizado (Expectativa de Performance), Facilidade de Uso (Expectativa de Esforço) e Influência Social foram percebidos pelos alunos como fatores influenciadores da Intenção de Uso do ambiente. A aproximação do domínio musical e da realidade social digital dos alunos teve influência nos construtos Oportunidades de Aprendizado, Motivação Hedônica, Influência Social e Facilidade de uso, relacionados à Intenção de Uso nos modelos UTAUT. Portanto, tanto o oferecimento de recursos sonoros quanto a disponibilização de recursos sociais dentro do ambiente estruturado utilizado influenciaram, através do impacto nos construtos mencionados anteriormente, na Intenção de Uso da plataforma Mignone pelos alunos, o que confirma a hipótese desta pesquisa.

\section{Trabalhos Relacionados}

Foram levantadas na literatura outras pesquisas na área de Informática na Educação que podem ser utilizadas diretamente ou indiretamente na Educação Musical.

Dotta [9] apresenta um estudo sobre o uso de mídias sociais como ambiente virtual de aprendizagem colaborativa. Como mídia social, o serviço GROU.PS é utilizado. No trabalho, o mesmo material de um determinado curso foi disponibilizado no AVA tradicionalmente utilizado na instituição de ensino participante (Tidia-AE) e em um espaço criado no serviço GROU.PS. Duas turmas realizaram o curso no GROU.PS, enquanto uma terceira realizou no AVA tradicional para que comparações fossem possíveis. Percebeu-se que os alunos das turmas que utilizaram a plataforma de rede social colaboraram mais entre si e utilizaram mais recursos multimídia em suas atividades do que os alunos da turma que fez o curso no AVA tradicional (Tidia-AE), onde as atividades entregues tiveram predominância textual. Os alunos também utilizaram espontaneamente os recursos sociais do GROU.PS para comunicarem entre si e publicarem links interessantes.

A rede social educativa REDU é um ambiente que oferece os recursos de uma rede social aliados a alguns recursos de um AVA tradicional. Possui ferramentas de comunicação síncrona (através de mensagens instantâneas) e assíncronas (como mural de recados, solicitação de ajuda, entre outras). Permite a disponibilização de recursos de vídeo, documentos de texto e exercícios pelo professor e seu acesso pelos alunos. Abreu et al. [1] apresentam um estudo de caso realizado com o REDU, onde apontam através de uma análise qualitativa que os alunos percebem as interações assíncronas através do mural como eficiente e também a ampliação do tempo de interação para além do período de aula presencial como positiva.

Marcon et al. [23] refletem sobre a utilização do ambiente de rede social online Facebook como uma Arquitetura Pedagógica, conceito que pode ser definido como a união de software educacional e abordagem pedagógica em um só ecossistema a ser utilizado no processo de aprendizagem [8]. No trabalho, os autores relatam a experiência do uso do Facebook em uma disciplina de pós- 
graduação. Como pontos positivos, indicam a veloz manifestação dos integrantes do grupo através da comunicação pela ferramenta mural, a existência de ferramentas que podem ser utilizadas em abordagens pedagógicas oferecidas pelo ambiente e a utilização de um espaço (Facebook) já conhecido pelos participantes através de outras atividades, como o lazer. Como ponto negativo, os autores citam o excesso de informações a que os alunos ficam expostos, o que faz com que os participantes necessitem estar cientes dos objetivos a serem alcançados e focados no seu atingimento. Após a análise da experiência, os autores consideram a utilização de redes sociais uma forte tendência nos processos de aprendizagem, inclusive como complemento aos AVA.

Em [3], o uso do AVA Moodle em conjunto com a rede social Facebook é relatado como positivo na aprendizagem dos alunos. Os autores indicam haver uma preferência pelo uso dos recursos oferecidos pela rede social e mostram em seu trabalho que, depois de certo período de curso, os alunos passaram a realizar as atividades pelo Facebook apenas.

O uso de redes sociais também pode ser observado na Educação Musical, como nos trabalhos de Gohn e Grosso [20] e Ribeiro [33]. Na pesquisa de Ribeiro [33], por exemplo, o ponto de contato dos alunos com o professor foi feito através de um grupo privado no Facebook e de um blog criado especificamente para a disciplina. $\mathrm{O}$ uso desta rede social foi uma sugestão dos próprios alunos e acatada pelo professor. Nessas duas pesquisas, pode-se ver a tentativa dos educadores musicais de proporcionar ao aluno uma melhor experiência de aprendizado, com o uso das TIC, mas com a preocupação centrada na efetividade deste aprendizado, utilizando abordagens tecnológicas diferentes das utilizadas antes e aproximando o aluno de sua "realidade digital", já praticada em outras atividades e como forma de lazer por eles.

A boa receptividade dos alunos aos recursos sociais, observada nos trabalhos acima mencionados, fortalece a parte da hipótese desta pesquisa que afirma que recursos sociais serão fatores influenciadores da Intenção de Uso de AVA pelos alunos. Entretanto, as pesquisas relacionadas foram realizadas sobre o uso de sistemas de redes sociais na Educação, mas sem foco na avaliação da aceitação pelos alunos ou da integração com OA especializados para o ensino de música.

Outro ponto importante deste trabalho é a utilização de recursos multimídia, ricos em áudio e embasados num modelo construtivista para Educação Musical. Aplicativos como Zorelha [22], MUSICON [4] e o Portal EduMusical [12], são exemplos de utilização satisfatória do Modelo C(L)A(S)P em ambientes virtuais de aprendizagem.
O Zorelha [22] foi construído como um OA a ser utilizado em cursos de musicalização infantil. Assim, sua finalidade é ser uma atividade complementar na formação musical de crianças de 4 a 9 anos. No projeto, o autor utiliza o modelo de cenários animados com a metáfora de um palco musical, onde acontece um show com uma banda de quatro integrantes.

Em um dos modos de uso do Zorelha, a criança pode escolher entre 4 músicas folclóricas conhecidas (Cai Cai Balão, Marcha Soldado, o Sapo não Lava o Pé e Atirei o Pau no Gato) em 4 arranjos diferentes (Forró, Rock, Samba e sons corporais). Com isso, são 16 possibilidades de exploração musical. Em cada uma das possibilidades de exploração, a criança pode escolher qual instrumento deseja ouvir, colocando o personagem que toca este instrumento no palco do Zorelha. Ao colocar o personagem no palco, a criança começa a ouvir o som do respectivo instrumento tocado por ele, ou seja, recebe feedback sobre a ação de ter alguém tocando aquele instrumento no palco, o que permite assimilar qual é o som do instrumento em questão.

Em relação ao modelo $\mathrm{C}(\mathrm{L}) \mathrm{A}(\mathrm{S}) \mathrm{P}$, o Zorelha explora o elemento "C" (criação), ao permitir que a criança faça a combinação que quiser com os instrumentos de uma determinada música, e o elemento "A" (apreciação), quando permite que a criança ouça 16 combinações musicais diferentes, com possibilidade de variações tímbricas.

O MUSICON [4] propôs a aplicação do modelo $\mathrm{C}(\mathrm{L}) \mathrm{A}(\mathrm{S}) \mathrm{P}$ em um ambiente de educação a distância para ensino de exercícios vocais. No trabalho, foi utilizado o AVA WebLearning e suas ferramentas disponíveis na época. O autor não fez nenhuma especialização nas ferramentas, utilizando somente o que era proporcionado pelo ambiente. No âmbito do curso, no entanto, o autor modelou aulas e jogos de aprendizagem seguindo a filosofia do Modelo C(L)A(S)P.

Um dos jogos propostos foi o de criação de melodias a partir de objetos geométricos. Estes elementos foram associados a sons específicos e o aluno deveria colocá-los na ordem que quisesse, produzindo novas melodias. No final do exercício, era solicitado o estudo vocal da melodia criada, para fins de apreciação. Na construção das aulas, Aristides testou a diminuição da quantidade de textos técnicos e o aumento do número de arquivos sonoros (MP3), que podiam ser escutados diretamente na página na ordem de sua aparição.

$\mathrm{O}$ autor cita que os tutores e alunos foram estimulados a colaborar através do chat e do fórum disponibilizado pela ferramenta WebLearning, no intuito de compartilharem seus conhecimentos e resultados de exercícios.

Aristides conclui que, mesmo utilizando o modelo $\mathrm{C}(\mathrm{L}) \mathrm{A}(\mathrm{S}) \mathrm{P}$ nas aulas modeladas, a falta de componentes 
especializados para o ensino de música no ambiente dificultou a transmissão do conhecimento e motivação dos alunos para utilização do ambiente.

O portal EduMusical [13] é um projeto em conjunto com programas da OSESP, Orquestra Sinfônica do Estado de São Paulo, para promover o ensino da música. Através de um endereço na internet, o interessado pode acessar um universo musical com diversos jogos, seguindo bem as ideias do modelo C(L)A(S)P e a filosofia construtivista. Para utilizar o portal, o aluno precisa ser instruído por um tutor externo a utilizar as ferramentas corretamente, pois ele não consiste em um curso ou uma aula de música, mas apenas em recursos que podem ser utilizados como complementos de aulas.

A plataforma VEMUS [38] é um ambiente focado no provimento de recursos para auxiliar a performance musical dos estudantes através da prática individual. Ela provê ferramentas para ouvir performances de referência de algumas obras musicais e permite que os alunos gravem suas próprias performances. A plataforma realiza uma avaliação automática das performances gravadas e envia feedbacks aos alunos. Assim, a VEMUS é um ambiente focado na questão da performance musical (parâmetro $P$ do $\mathrm{C}(\mathrm{L}) \mathrm{A}(\mathrm{S}) \mathrm{P}$ ) que também explora a apreciação (parâmetro A) ao permitir ouvir as performances de referência. Porém, o modelo $\mathrm{C}(\mathrm{L}) \mathrm{A}(\mathrm{S}) \mathrm{P}$ não é referenciado diretamente pelo autor da plataforma.

Alguns pesquisadores realizaram tentativas de utilizar o software Skype na realização de atividades de maneira síncrona [34]. Porém, há questões relacionadas à qualidade do áudio transmitido, que é dependente de equipamentos ainda caros e limita a transmissão de detalhes essenciais como nuances de interpretação [19] [33], além da questão do atraso na transmissão do vídeo - chamado de delay - que torna difícil a realização de algumas atividades que necessitam de respostas imediatas, como é o caso da prática em conjunto. Uma solução ainda em desenvolvimento para este último problema é o projeto LOLA (LOw LAtency audio visual streaming system), que provê uma rede de baixo atraso e específica para uso em sessões musicais síncronas.

Diante destes trabalhos, é possível perceber que já existem pesquisas relacionadas ao uso do modelo $\mathrm{C}(\mathrm{L}) \mathrm{A}(\mathrm{S}) \mathrm{P}$, de forma direta ou indireta, na Educação Musical auxiliada por computador. Além disso, a boa recepção por parte dos alunos citada em algumas das pesquisas reforça a ideia de que recursos $\mathrm{C}(\mathrm{L}) \mathrm{A}(\mathrm{S}) \mathrm{P}$ podem influenciar na aceitação de um AVA especializado para Educação Musical. Porém, com exceção da plataforma VEMUS, em nenhum dos trabalhos expostos há uma preocupação na criação de ambientes virtuais de aprendizagem específicos para Educação Musical. Tampouco preocupam-se com a identificação de critérios de aceitação dos ambientes pelos alunos. A maioria dos trabalhos preocupa-se com o desenvolvimento de OA para o aprendizado de música, mas não com os ambientes de aprendizagem onde serão expostos. Além disso, os trabalhos comentados exploram pouco as possibilidades de interação social e carecem do oferecimento de recursos colaborativos para os alunos, com exceção do Editor Musical, um dos aplicativos disponíveis no Portal EduMusical.

Sobre o viés da colaboração, o que se percebe é que há cada vez mais softwares específicos para o domínio musical e que podem ser utilizados no processo de aprendizagem colaborativa do aluno de música [18]. Sistemas como NoteFlight ${ }^{18}$, OhmStudio ${ }^{19}$ e ambientes sociais como SoundCloud ${ }^{20}$, IndabaMusic ${ }^{21}$ e Musescore ${ }^{22}$ são exemplos de ferramentas com grande potencial para uso em atividades educacionais e que mostram a ampliação da oferta destes tipos de software no mercado ultimamente.

Além disso, trabalhos como o realizado por Nikolaidou [28] mostram resultados positivos no uso de recursos colaborativos na educação musical. O autor aplicou um modelo de análise do discurso, chamado ComPLuS, em um estudo de caso sobre composição colaborativa, com o objetivo de mapear tipos de discurso a certos tipos de ação na composição conjunta. A pesquisa foi realizada com crianças de 7 a 12 anos que colaboraram em pares, de forma presencial, utilizando como software de apoio um editor de partituras não colaborativo, que exigia conhecimento de notação formal musical. A dinâmica de composição colaborativa em pares foi gravada em vídeo e o discurso das crianças foi transcrito e analisados através do modelo ComPLuS. Cada tipo de fala foi relacionado a possíveis ações musicais. Após esta análise, foi efetuada uma etapa de correlação estatística, identificando a relação de um tipo de fala com suas consequentes ações.

Uma das conclusões do estudo de caso é que quanto mais os pares sabiam sobre música, maior foi o número de ações que eram executadas. Além disso, quanto mais os pares se envolviam no procedimento de tentativa e erro, mais eles colaboravam entre si, mostrando um grande número de ações conjuntas do tipo tácita (sem explicação explícita) durante a dinâmica.

Outra importante conclusão é que crianças com faixa etária mais próxima dos 11 anos se dispõem a externalizar

\footnotetext{
18

19

http://www.noteflight.com

http://www.ohmstudio.com

http://www.soundcloud.com

http://www.indabamusic.com

http://www.musescore.com
} 
mais as suas ideias durante uma atividade de composição colaborativa mediada por computador. Este fato pôde ser concluído devido ao alto índice do tipo de diálogo "proposta como uma oferta" com pares dessa idade.

O Editor Musical [12] é um software onde os alunos podem criar músicas de forma colaborativa através de uma representação musical informal. A notação musical convencional não é utilizada e, ao invés disto, quadrados e linhas representando alturas, em um estilo "piano roll", são apresentados. A ideia é que os alunos concentrem-se mais no aspecto material da música, ou seja, timbre de instrumentos, alturas (notas), durações e ritmo, do que a forma de como representar tudo isto em uma partitura musical. $\mathrm{O}$ ambiente é proposto para iniciação musical de crianças e, por isso, utiliza figuras e animações para chamar a atenção desta faixa etária. O Editor Musical é um dos aplicativos $\mathrm{C}(\mathrm{L}) \mathrm{A}(\mathrm{S}) \mathrm{P}$ disponibilizados no portal EduMusical [13].

Já o projeto CODES [25], é um ambiente de produção musical colaborativa direcionado a alunos leigos. Para representação musical, é utilizada uma notação não formal baseada na prototipação, onde a nota musical é representada através de um plano cartesiano, onde o eixo y indica a altura da nota e o eixo $\mathrm{x}$ a sua duração. A representação final é parecida com a notação "piano roll".

Para a percepção da colaboração, o CODES utiliza vários mecanismos de suporte. O registro $(\log )$ de ações de cada usuário, que pode ser consultado por todos os colaboradores, o que permite que todas as ações realizadas na composição da música em questão sejam visualizadas por todos os envolvidos.

Além disso, o CODES utiliza uma metáfora de marcas de ações em cada elemento modificado por um usuário. Um protótipo que acabou de ser inserido recebe a marca de uma estrela, informando aos outros que é um elemento novo, por exemplo. Além destas marcas, cada usuário é identificado por uma cor diferente e suas contribuições ficam em camadas distintas umas das outras, envolvidas por um retângulo da cor de cada colaborador.

O CODES também traz um mecanismo de argumentação, onde é possível a realização de debates estruturados entre os participantes e a decisão pode ser tomada por todos em conjunto, considerando a visão de cada um individualmente.

Uma proposta similar de representação foi abordada por McCarthy [24] no projeto Networked DrumSteps. O objetivo do ambiente era o ensino de percussão a distância, de forma colaborativa. $\mathrm{O}$ autor focou no uso da filosofia construtivista e desenvolveu um sistema em que o aluno interage de forma abstrata com conceitos musicais próximos à realidade do aluno leigo em música. Desta forma, a intenção é que o aluno aprenda percussão através da facilidade proporcionada pela abstração proposta, já que esta relaciona novos conceitos musicais a conceitos já conhecidos, como escadas, gravidade e obstáculos.

O uso do Networked DrumSteps consiste na criação colaborativa de ritmos através do uso de bolas, degraus e obstáculos. A bola desce os degraus indicados, devido à força da gravidade, e cada obstáculo cria um timbre diferente. Muitas bolas podem ser colocadas para descerem escadas simultaneamente ou em tempos diferenciados.

O sistema i-maestro [15] é outro ambiente colaborativo para estudos musicais. Nele, existem exercícios de treinamento de audição, onde o aluno deve escrever qual é a nota e qual a duração do som que está sendo ouvido. $\mathrm{Na}$ proposta do i-maestro, as notas a serem descobertas vão sendo tocadas em sequência, com a possibilidade de pausa e continuação pelo estudante. Durante a execução dos exercícios, as notas escritas por outros estudantes são exibidas a todos os alunos, assim como o progresso individual de todos. Desta forma, existe uma colaboração de mensagens musicais, o que pode provocar reflexão e negociação do aluno que as percebe. Ao final do exercício, os acertos e erros são classificados e pontuados.

Para categorizar a abrangência dos trabalhos levantados, foi realizada uma classificação em relação à exploração de 5 elementos, todos utilizados nesta pesquisa: (i) Recursos Multimídia, (ii) Recursos Sociais, (iii) Modelos de Estruturação, (iv) Arquitetura de Reuso e (v) e Preocupação com Integração. A Tabela 1 ilustra o comparativo com os principais trabalhos. Apenas a Plataforma Mignone analisou a intenção de uso por parte dos alunos.

\begin{tabular}{|l|l|c|c|c|c|c|}
\hline \multicolumn{1}{|c|}{ Trabalho } & \multicolumn{1}{|c|}{ Referência } & Multimídia & Social & Estruturação & Reuso & Integração \\
\hline GROU.PS & http://grou.ps & $\mathrm{X}$ & $\mathrm{X}$ & & & \\
\hline REDU & http://redu.com.br & $\mathrm{X}$ & $\mathrm{X}$ & $\mathrm{X}$ & $\mathrm{X}$ & \\
\hline Facebook & http://facebook.com & $\mathrm{X}$ & $\mathrm{X}$ & & & \\
\hline Zorelha & JESUS et al., 2010 & $\mathrm{X}$ & & $\mathrm{X}$ & $\mathrm{X}$ & \\
\hline EduMusical & FICHEMAN et al., 2003 & $\mathrm{X}$ & & $\mathrm{X}$ & $\mathrm{X}$ & $\mathrm{X}$ \\
\hline VEMUS & TAMBOURATZIS et al., 2008 & $\mathrm{X}$ & & $\mathrm{X}$ & $\mathrm{X}$ & $\mathrm{X}$ \\
\hline IMaestro & FROSINI et al., 2008 & $\mathrm{X}$ & $\mathrm{X}$ & $\mathrm{X}$ & $\mathrm{X}$ & \\
\hline
\end{tabular}




\begin{tabular}{|c|c|c|c|c|c|c|}
\hline DrumSteps & McCARTHY, 2005 & $X$ & $X$ & $X$ & $X$ & \\
\hline \multicolumn{2}{|c|}{ Plataforma Mignone } & $x$ & $x$ & $x$ & $x$ & $x$ \\
\hline
\end{tabular}

Tabela 1: Comparativo com Trabalhos Relacionados

\section{Conclusões}

$\mathrm{Na}$ análise, foi visto que recursos de manipulação de som influenciam os construtos Oportunidades de Aprendizagem, Motivação Hedônica e Facilidade de Uso, assim como que os recursos sociais influenciam na Motivação Hedônica, Facilidade de Uso e Influência Social. Como tais recursos foram oferecidos propositalmente na Plataforma Mignone, acredita-se que a Aproximação do Domínio e a Aproximação da Realidade Social Digital sejam dois novos construtos que influenciam a Intenção de Uso de ambientes de Educação Musical, e podem ser adicionadas ao modelo UTAUT na avaliação de aceitação neste domínio.

É importante ressaltar que, além da aceitação, os alunos relataram ter gostado bastante da experiência. Todos os 13 entrevistados elogiaram o ambiente e as atividades nas entrevistas. Além disso, a professora relatou um feedback muito positivo de todos os alunos que participaram da pesquisa, indicando ainda que alunos de outras turmas que ficaram de fora do estudo quiseram muito participar quando viram como era o ambiente.

Quando solicitados a comentar sobre os conceitos aprendidos, os muito dos participantes foram bem além do objetivo, fazendo relações com outras matérias, enriquecendo com exemplos ou indicando que a experiência foi prazeirosa e empolgante. Além disso, a professora responsável viu nos OA e AVA construídos uma oportunidade de ensinar de forma eficaz vários dos conteúdos que costuma abordar, em turmas com diferentes graus de maturidade, e já está utilizando-os em novas classes.

São contribuições deste trabalho: (i) a Plataforma Mignone e seu AVA para Educação Musical Básica, que integra a Arquitetura Mignone e o modelo 3C$\mathrm{C}(\mathrm{L}) \mathrm{A}(\mathrm{S}) \mathrm{P}$, resultado de um estudo teórico minucioso e de grande esforço de implementação; (ii) a detecção da influência indireta da Aproximação do Domínio, através do oferecimento de recursos sonoros, e da Realidade Social Digital, através da disponibilização de recursos sociais, na Intenção de Uso de ambientes de Educação Musical; e (iii) o modelo de análise do discurso utilizado, tomando como base construtos de aceitação de tecnologias junto à metodologia MEDS, que resultou numa análise qualitativa interessante e que pode ser utilizada em outras pesquisas, principalmente na área de Informática na Educação.

Este trabalho teve foco na visão de aceitação do am- biente por parte dos alunos. Porém, é importante avaliar também a aceitação do ambiente na visão dos professores, que são os responsáveis pelas estratégias pedagógicas, atividades e dinâmicas de utilização tanto dos recursos oferecidos pelo AVA quanto dos OA nele contido. Assim, um possível trabalho futuro é explorar quais são os fatores que influenciam na Intenção de Uso de AVAs do professor/tutor de Educação Musical.

O AVA construído pode também ser utilizado como um ambiente de Personal Learning Environment (PLE) para Educação Musical, onde o foco é a aprendizagem continuada e independente de instituição. Nesta linha, o endereço público (URL) do AVA pode ser acessado por qualquer aluno interessado e utilizado como seu PLE. Porém, são necessários estudos adicionais para entender o comportamento do estudante neste contexto.

Do ponto de vista da colaboração, pode-se trabalhar no oferecimento de mais recursos de interação, como composição colaborativa, troca de informações musicais em tempo real e a integração com outros ambientes relevantes, como Youtube por exemplo. Tais recursos podem melhorar ainda mais a aceitação da Plataforma Mignone pelos alunos.

Além da adição de novos recursos, outros trabalhos podem considerar a aplicação de métodos e técnicas similares às aplicadas neste trabalho em outras áreas de educação. Dessa forma seria possível um único ambiente atender vários tipos de cenários educativos, adequando-se a cada um deles de acordo com a necessidade.

\section{Agradecimentos}

Este trabalho foi parcialmente apoiado pela FAPERJ $(\mathrm{E}-26 / 102.256 / 2013$ e E-26/170028/2008) e CNPq (57.128/2009-9).

\section{Referências}

[1] J. Abreu, L. Claudeivan, F. Veloso, A. S. Gomes. Análise das Práticas de Colaboração e Comunicação: Estudo de Caso utilizando a Rede Social Educativa Redu. In Anais do Workshop de Informática na Escola, Aracaju, páginas 12461255, 2011.

[2] E. Alberich-Artal, A. Sangrà. Virtual Virtuosos: A Case Study in Learning Music in Virtual 
Learning Environments in Spain. European Journal of Open, Distance and E-Learning, 2012(1): 1-9, 2012.

[3] R. Araújo, T. Panerai. Relato de Experiência de Blended Learning: O Moodle e o Facebook como Ambientes de Extensão da Sala de Aula Presencial. In Anais do Workshop de Informática na Escola, Rio de Janeiro, páginas 1-11, 2012.

[4] M. Aristides. MUSICON: Uma plataforma construtivista para ensino de música via internet, Dissertação de Mestrado, Universidade Federal do Estado do Rio de Janeiro (UNIRIO), Nov 2002.

[5] G. Attwell. Personal Learning Environments the future of eLearning. eLearning Papers, 2(1): 1-8, 2007.

[6] J. Bourgonjon, M. Valcke, R. Soetaert, T. Schellens. Students' perceptions about the use of video games in the classroom. Computers \& Education, 54(4): 1145-1156, 2010.

[7] P. Burnard, B. A. Younker. Investigating children's musical interactions within the activities systems of group composing and arranging: an application of Engestrom's activity theory. International Journal of Educational Research, 47(1):60-74, 2008.

[8] M. J. S. Carvalho, R. A. de Nevado, C. S. de Menezes. Arquiteturas pedagógicas para a educação a distância. In R. A. de Nevado, M. J. S. Carvalho, C. S. de Menezes (Orgs.) Aprendizagem em rede na educação a distância: estudos e recursos para formação de professores, páginas 36-52, Ricardo Lenz Editor, Porto Alegre. 2007.

[9] S. Dotta. Uso de uma Mídia Social como Ambiente Virtual de Aprendizagem. In Anais do Simpósio Brasileiro de Informática na Educação, Aracaju, páginas 610-619, 2011.

[10] C. A. Ellis, S. J. Gibbs, G. L. Rein, Groupware Some Issues and Experiences. Communications of the ACM, 34(1):38-58, 1991.

[11] J. N. Fernandes. Análise da didática da educação musical nas escolas públicas da cidade do Rio de Janeiro. Tese de Doutorado, Universidade Federal do Rio de Janeiro, 1998.

[12] I. K. Ficheman, R. A. Lipas, S. E. Krüger, R. D. D. Lopes. Editor Musical: uma Aplicação para a Aprendizagem de Música apoiada por Meios Eletrônicos Interativos. In Anais do Simpósio Brasileiro de Informática na Educação, Rio de Janeiro, páginas 176-185, 2003.

[13] I. Ficheman, S. Kruger, R. Lopes, (2004) Editor Musical: uma pesquisa sobre software para com- posição musical individual e colaborativa. http://www.edumusical.org.br/siteprof/textos.php ?texto=FKL, Nov. 2004.

[14] M. Fishbein, I. Ajzen Belief, Attitude, Intention and Behavior: An Introduction to Theory and Research. Addison-Wesley, 1975.

[15] F. Frosini, N. Mitolo, P. Nesi, M. Paolucci. Collaborative Solution for Music Education. In Proc International Conference on Automated Solutions for Cross Media Content and MultiChannel Distribution (AXMEDIS), Florença, páginas 71-78, 2008.

[16] H. Fuks, A. Raposo, M. A. Gerosa, M. Pimentel, C. J. P. Lucena. The 3C Collaboration Model. In N. Kock (ed.) Encyclopedia of E-Collaboration, páginas 633-644, IGI Global, Hershey. 2008.

[17] C. Galdino. Formação do Professor de Música: Demandas Novas e Emergentes. Salto para o Futuro: Educação Musical Escolar, 21(8): 3440, 2011.

[18] D. Gohn. Tendências na educação à distância: os softwares on-line de música. Revista Opus, 16:113-126, 2010.

[19] D. Gohn. Ensino e aprendizagem de bateria no Brasil: de Luciano Perrone à EAD. In Anais do XX Congresso Nacional da Associação Brasileira de Educação Musical, Vitoria, 2011.

[20] D. Gohn, P. K. Grosso. Proposta de um curso on-line de apreciação musical. In XX Congresso Nacional da Associação Brasileira de Educação Musical, Vitoria, 2011.

[21] G. Guest, B. Arwen, J. Laura. How many interviews are enough? An experiment with data saturation and variability. Field Methods, 18(1):5982, 2006.

[22] E. A. Jesus, M. Z. Uriarte, A. L. A. Raabe. Zorelha: Um Objeto de Aprendizagem para Auxiliar o Desenvolvimento da Percepção Musical em Crianças de 4 a 6 anos. Revista Brasileira de Informática na Educação, 18:91-105, 2010.

[23] K. Marcon, J. B. Machado, M. J. S. Carvalho. Arquiteturas Pedagógicas e Redes Sociais: Uma experiência no Facebook. In Anais do Simpósio Brasileiro de Informática na Educação, Rio de Janeiro, páginas 1-10, 2012.

[24] C. Mccarthy, J. Bligh, K. Jennings, B. Tangney. Virtual collaborative learning environments for music: networked drumsteps. Computers \& Education, 44(2):173-195, 2005.

[25] E. Miletto, M. Pimenta. Music Creation by Novices should be both Prototypical and Cooperative - Lessons Learned from CODES. In Anais do Simpósio Brasileiro de Computacão Musical, 
Recife, páginas 1-12, 2009.

[26] M. Moore, G. Kearsley. Educação à distância: Uma visão integrada. Thomson Learning, São Paulo. 2007.

[27] A. M. Nicolaci-Da-Costa, D. Romão-Dias, F. Di Luccio. Uso de Entrevistas On-Line no Método de Explicitação do Discurso Subjacente (MEDS). Psicologia: Reflexão e Crítica, 22(1):36-43, 2007.

[28] G. N. Nikolaidou. ComPLuS model: A new insight in pupils' collaborative talk, actions and balance during a computer-mediated music task. Computers \& Education, 58(2):740-765, 2012.

[29] F. Pinhati, S. W. M. Siqueira, A. J. Mendes, A. Cardoso. LO-C(L)A(S)P: a Model for Supporting the Development of Learning Objects with Sound Manipulation and Social Resources for Music Education. In Proceedings of the 19th Americas Conference on Information Systems, Chicago, páginas 1-10, 2013.

[30] F. Pinhati,, S. W. M. Siqueira. Educação Musical Apoiada por Computador: Um Levantamento da Situação Atual e uma Proposta de Especialização de Ferramentas Existentes. In Anais do $13^{\circ} \mathrm{Sim}$ pósio Brasileiro de Computação Musical, Vitória, páginas 1-12, 2011.

[31] F. Pinhati, S. W. M. Siqueira. Plataforma Mignone: Uma Arquitetura para Ambientes Virtuais e um Modelo para Construção de Objetos de Aprendizagem Especializados para Educação Musical. In Anais dos Workshops do Congresso Brasileiro de Informática na Educação, Campinas, páginas 1-10, 2013.

[32] M. Prensky. Digital natives, digital immigrants, Part II: Do they really think differently?, On the Horizon, 9(6):1-9, 2001.

[33] G. M. Ribeiro. Integração de mídias digitais na elaboração de material didático para aulas de violão a distância. In Anais do $X X$ Congresso Nacional da Associação Brasileira de Educação Musical, Vitória, 2011.

[34] G. M. Ribeiro, P. D. A. Braga. Aprendizagem por Videoconferência nas Aulas Coletivas de Instrumento. In Anais do XIX Congresso Nacional da Associação Brasileira de Educação Musical, Goiânia, páginas 455-464, 2010.

[35] M. L. Serafine. Music as cognition. The development of thought in sound. Columbia University Press, New York, 1988.

[36] S. D. Smith, J. B. Caruso. ECAR Study of Undergraduate Students and Information Technology. Relatório Técnico EDUCAUSE Center for Applied Research, 2010.
[37] K. Swanwick. A Basis for Music Education. Routledge, London, 1979.

[38] G. Tambouratzis, K. Perifanos, I. Voulgari, A. Askenfelt, S. Granqvist, K. F. Hansen, Y. Orlarey, D. Fober, S. Letz. VEMUS: An Integrated Platform to Support Music Tuition Tasks. In Proceedings of the Eighth IEEE International Conference on Advanced Learning Technologies, Santander, páginas 972-976, 2008.

[39] V. Venkatesh, M. G. Morris, G. B. Davis, F. D. Davis. User acceptance of Information Technology: Toward a Unified View. MIS Quarterly, 27(3):425-478, 2003.

[40] V. Venkatesh,, J. Thong, X. Xu. Consumer acceptance and use of information technology: extending the unified theory of acceptance and use of technology. MIS Quarterly, 36(1):157178, 2012.

[41] L. S. Vygotsky. Thought and Language. MIT Press, Cambridge, 1962.

[42] Todos pela Educação. Anuário Brasileiro da Educação Básica 2014, Editora Moderna, 2014. http://www.todospelaeducacao.org.br//arquivos/b ibliote-

ca/anuario brasileiro_da_educacao_basica_2014 pdf. Acesso em Janeiro de 2015.

[43] D. S. White, A. Le Cornu. Visitors and residents: A new typology for online engagement. First Monday, 16(9), 2011.

[44] T. Panitz. A Definition of Collaborative vs Cooperative Learning, Deliberations, 1996. http://ccti.colfinder.org/sites/default/files/a_defin ition of collaborative vs cooperative learning. pdf. Acesso em Janeiro de 2015. 